Then for $u=-1.16,2 u=z=-2.33 . \quad z-2 / 3^{\circ}=x=-3$. For the value $u=-.16, x=-1$; and for the value $u=1.3$, $x=2$. Of course, the values offered here in this sample equation are exact and obtained for the purpose of this paper by accurate and actual calculation, while such exactness is not expected of graphical computation, which is more frequently only approximate.

It will be observed that according as the point $(s, t)$ falls outside of, on the boundary of, or within the triangular shaped region on the left, one, two, or three values of $u$ can be read, and the corresponding cubic equation has one real root only, three real roots two of which are equal, or three distinct real roots.

The chart is merely an illustration of the method. A more elaborate and extensive chart would be accordingly more useful as, by it, it would be possible to solve cubic equations more conveniently and with a higher degree of approximation.

(Note by Math. Ed.-For other examples of the use of graphic charts see, Graphical and Mechanical Computation. Lipka, $\$ 4.00,1918$, John Wiley and Sons, Ine,; The Construction of Graphical Charis, Peddle, 1910, MeGraw-Hill Book Co., How to Make And Use Graphic Charts, Haskell, \$5.00.)

\title{
HOW TO TELL GOOD YEAST-IT SHOULD BE FREE FROM DRYNESS, GAS AND OFFENSIVE ODOR.
}

BY Dr. LEONARD K. HirshberG.

It is a simple matter to tell the difference between good fresh yeast eakes and the huge old, dry eircular loaf cakes found in a lot of New York East Side shops, and foreign groceries in other cities. Yeast cakes, wrapped in silver foil are almost unknown in these shops, as their patrons, not aware that yeast is a perishable product, do not demand fresh goods. The yeast loaf is sliced down like cheese, and slices are sold until the entire loaf is gone regardless of the length of time it lays on the counter.

Many of the upset stomachs and other digestive disturbances blamed upon one thing or another exeept the right cause, are really due at times to yeast used in bread, home brew and cakes, which is not the fresh grocery yeast cakes carefully kept in silver foil. The latter are supplied to dealers daily, and are always fresh.

Almost everybody eats yeast these days for beautifying the complexion, warding off sickness, and increasing their powers of endurance, etc.

It is therefore a matter of sensible precaution to follow the advice of the Bureau of Chemistry and the Department of Agriculture and see to it that you obtain the fresh, small individual cakes of yeast at a good grocery store, and thus avoid the fatalities or disturbances which pass under the blame of autointoxication, indigestion, food poisoning and the like.

In all of the experiments conducted by experts, it has been found that the large yeast masses from which foreign stores slice off, and sell dry portions, the stale yeast is not to be trusted, while the small square cakes are always safe.

In this small cake you are sure to obtain the fresh active yeast rich in water soluble vitamines, those essential elements of perfect health and activity. 